REVISTA CHILENA DE LITERATURA

Noviembre 2020, Número 102, 223-247

\title{
KAFKA Y LA ENFERMEDAD. ENTRE LA REALIDAD Y LA ESCRITURA
}

\author{
Josep Ballester Roca \\ Universitat de València \\ Valencia, España \\ Josep.Ballester@uv.es \\ Noelia Ibarra Rius \\ Universitat de València \\ Valencia, España \\ Noelia.Ibarra@uv.es
}

\section{RESUMEN / ABSTRACT}

Los autores estudian uno de los aspectos menos explorados de la obra del escritor checo en lengua alemana, Franz Kafka: la enfermedad en su discurso literario e íntimo. Así, los investigadores afrontan el análisis de su obra literaria y escritos personales con el objetivo de descubrir las diferentes representaciones de la enfermedad que en él figuran y la íntima relación que estas imágenes y metáforas establecen con su trayectoria vital y artística

Palabras ClaVE: Kafka, escritura, enfermedad, literatura.

\section{KAFKA AND DISEASE. BETWEEN REALITY AND WRITING}

The authors study one of the least explored aspects of the work of the Czech writer in German language Franz Kafka: the disease in his literary and intimate discourse. As well, the researchers face the analysis of his literary and personal work with the objective of discovering the different representations of the disease and the strong relationship that these images and metaphors have in his life and his art.

KEYWORDS: Kakfa, writing, disease, literature.

Recepción: 10/05/2018

Aprobación: 27/07/2018 


\section{INTRODUCCIÓN}

En la Ciudad Vieja de Praga, un tres de julio de 1883, nace Franz Kafka, y muere un mes antes de cumplir los cuarenta y tres años. Una existencia por tanto, más bien breve. Sus documentos personales reflejan su punto de vista respecto a la medicina tradicional, la naturista o los médicos, asimismo, incluyen numerosos comentarios en torno a diferentes afecciones, en ocasiones no identificadas como enfermedades concretas: "Hace bastante tiempo que me quejo de que siempre estoy enfermo pero no tengo nunca una enfermedad concreta que me fuerce a guardar cama" (Diario, 24 noviembre 1911) y en otras alusiones se refiere a dolencias graves, como la aparición de la tuberculosis que finalmente le provocó la muerte. En esta línea podemos aducir un fragmento de 1907 en el que ya le presenta a su amigo Max Brod algunos síntomas de su malestar como si tuviera vida propia:

Justo ahora han comenzado los dolores de estómago... Todo lo que ponga se vuelve contra mí, todo lo que está en mi contra deja de ser de mi propiedad. $\mathrm{Si}$, por ejemplo, me duele el estómago, ya no es mi estómago, sino algo que no se diferencia substancialmente de un individuo extraño que se divierte dándome una paliza (Carta a Max Brod, 4 marzo 1907).

La relevancia de la fuente inagotable de comentarios y pensamientos de este escritor checo en lengua alemana que en definitiva constituyen los diarios y la correspondencia radica en la posibilidad que nos brindan de aproximarnos a su personalidad y preocupaciones en diversos ámbitos, tanto el más personal como el social y, sobre todo, creativo. Frente a las diferentes perspectivas desde las que se ha interpretado su obra y documentación personal, así el punto de vista social, sionista, marxista e incluso desde el psicoanálisis, todavía no contamos con suficientes investigaciones en las que se aborde en profundidad el análisis de la enfermedad en sus textos más personales y su relación con los ficcionales, la representación y función de aquellas posibles dolencias sugeridas desde los escritos, como la anorexia, la depresión o los fuertes dolores de cabeza que padeció.

Por este motivo, nuestra hipótesis de partida es la existencia de una íntima relación entre la representación de la enfermedad en su discurso literario e íntimo y, en consecuencia, el objetivo de estas páginas estriba en descubrir las conexiones entre las figuraciones de la enfermedad en su obra literaria 
y en sus escritos personales y las distintas interrelaciones de su universo de imágenes, figuras, tópicos y metáforas con su trayectoria vital y artística.

\section{HISTORIA CLÍNICA A PARTIR DE SUS TEXTOS}

Las diferentes referencias plasmadas en sus escritos nos permiten leerlos como una suerte de historia clínica, plagada de diferentes menciones, como su descontento ante el insomnio y el dolor de cabeza punzante que se incrementa, sobre todo, a partir de 1913: "Una nueva cefalea de un tipo, hasta ahora desconocido. Un dolor corto y punzante sobre el ojo derecho. Esta mañana apareció por primera vez" escribe el 16 de septiembre de 1915 en su diario. Al respecto, dos neurólogos suecos, T. Ekbom y K. Ekbom (2004), apuntan en su trabajo la hipótesis de ataques de cefalea en racimo o cefalea de Horton como explicación a las jaquecas de Kafka. Esta tipología está caracterizada como muy severa, sin embargo, el autor nunca se medicó al respecto, ya que desconfiaba de esta posibilidad y de la profesión médica en general: "Es indudable que los médicos son estúpidos; mejor dicho, no son más estúpidos que otra gente, pero sus pretensiones son absurdas. Con todo, hay que hacerse a la idea de que se van estupidizando más y más desde el instante en que uno se pone en sus manos, y lo que el médico exige en este momento no es ni muy estúpido ni imposible. Lo imposible es que usted se enferme realmente y esa imposibilidad debe subsistir. ¿En qué ha cambiado su vida desde que habló con el médico?" (Carta a Milena Jesenská, 18 mayo 1920). Recordemos que tanto en El proceso (1925) como en La transformación (1915) aparecen personajes que experimentan torturas o dolores lacerantes en la misma época que él atravesaba periodos de esta cefalea de Horton. Los sufrimientos padecidos por el escritor habrían encontrado su correlato en estos personajes, a manera de explicación metafórica de sus tribulaciones, según apuntan los investigadores suecos, en detrimento de las hipótesis interpretativas que han vinculado las dolorosas explicaciones con una suerte de sadismo.

Manfred M. Fichter (1987, 1988), del Departamento de Psiquiatría de la Universidad de Munich, publicó unas investigaciones en torno a la anorexia nerviosa del escritor que suscitaron mucha curiosidad tanto en el ámbito psiquiátrico como en el literario. Su idea respecto a la anorexia nerviosa de Kafka parte del relato "Un artista del hambre" (1922), en el que se narra la historia de una atracción de feria, un personaje que basa su identidad en la capacidad de prescindir de la comida, lo que le provoca una sensación de superioridad sobre el resto de los seres humanos de la que en realidad se 
alimenta. Por tanto, el éxito del espectáculo le proporciona la satisfacción necesaria para sobrevivir, sin embargo, cuando decae el interés del público por los ayunadores y, en consecuencia, el espectáculo deja de ser rentable, el personaje muere por inanición en un estado de total abandono:

Los más hermosos rótulos llegaron a ponerse sucios e ilegibles, fueron arrancados, y a nadie se le ocurrió renovarlos. La tablilla con el número de los días transcurridos desde que había comenzado el ayuno, que en los primeros tiempos era cuidadosamente mudada todos los días, hacía ya mucho tiempo que era la misma, pues al cabo de algunas semanas este pequeño trabajo habíase hecho desagradable para el personal; y de este modo, cierto que el ayunador continuó ayunando, como siempre había anhelado, y que lo hacía sin molestia, tal como en otro tiempo lo había anunciado; pero nadie contaba ya el tiempo que pasaba; nadie, ni siquiera el mismo ayunador, sabía qué número de días de ayuno llevaba alcanzados, y su corazón se llenaba de melancolía (Kafka, "Un artista del hambre" en Obras escogidas, 352).

El ayuno y el hambre figuran también como tema en otros relatos, como por ejemplo, en uno editado el mismo año, "Investigaciones de un perro" (1922). En un momento determinado el animal protagonista afirma: "La ruta a través del hambre; lo más elevado se conquista sólo por el sacrificio, y el mayor sacrificio es entre nosotros el hambre voluntaria" (Kafka, La metamorfosis y otros relatos, 87). También en La transformación (Kafka, op cit.) el hambre experimentada por Gregor Samsa adquiere protagonismo en los términos que siguen:

Así permaneció toda la noche, parte en un semisueño, del que le despertaba con sobresalto el hambre, y parte también presa de preocupaciones [...] Pero, si por ella misma no lo hacía, él prefería morirse de hambre antes que llamarle la atención sobre esto, no obstante sentir unas ganas tremendas de salir de debajo del sofá, arrojarse a sus pies y suplicarle le trajese algo bueno de comer (32).

Asimismo, destacan las frecuentes alusiones al aspecto físico de Kafka en sus cartas y diarios, sobre todo, en relación con la ausencia de comentarios respecto a la presencia de un trastorno del esquema corporal, esto es, de lo que se considera la alteración fundamental de la anorexia nerviosa, tal y como constata Luis M. Iruela (2011). La única nota estriba en el apunte de una cierta vergüenza respecto a su extrema delgadez: 
Lo que sí es seguro es que mi estado físico constituye uno de los principales obstáculos a mi progreso. Con un cuerpo así no es posible conseguir nada. Tendré que acostumbrarme a su fracaso permanente. [...] Cómo va a poder mi débil corazón, en el que vengo sintiendo punzadas en los últimos tiempos, empujar la sangre a todo lo largo de estas piernas (Diario, 22 noviembre 1911).

Por el contrario, dejó numerosas anotaciones en las que se reflejan los momentos de profunda depresión que atravesaba con frecuencia. Así, como muestra podemos aducir una carta del 31 de diciembre de 1912 en la que le transmite a Felice su estado: "A las 8 de la tarde de hoy, hallándome aún en la cama, ni cansado ni descansado, pero incapaz de levantarme, agobiado como estaba por toda esta fiesta de San Silvestre que comenzaba a mi alrededor, hallándome en la cama y con tanta tristeza, abandonado como un perro". De sus palabras se desprende la profunda interconexión entre su estado anímico y el físico, y en consecuencia, sus efectos en el proceso creativo. A tal efecto, uno de sus mejores biógrafos, Reiner Stach, en una entrevista comenta:

Sufrió neurosis y depresiones, y a la vez se recetó y se curó escribiendo. Esto lo calmaba y le hacía feliz, la cosa cierta, pero es la desproporción entre esfuerzo y el resultado es casi estrafalario: vivió 40 años y 11 meses y sólo terminó 350 páginas; el resto, 3.400 , quedó sin terminar [...] cuando uno es feliz no necesita escribir, y Kafka sólo escribía en su diario si estaba deprimido. Pero también tuvo momentos felices, sabemos que en su vida normal no daba la impresión de estar atormentado. Era amable y sociable, aunque no, desde luego, transparente. Llevaba una máscara dulce, pero era impenetrable. Conscientemente, no dejaba que nadie viera su lado oscuro, ni sus amigos: su depresión era suya, y sólo la compartió con Felice Bauer, porque pensaba que si iba a vivir con ella, era justo que lo supiera (Mora 2).

La reflexión en torno a la salud figura con frecuencia en sus páginas con diferentes conclusiones del autoanálisis realizado, desde la autopercepción de sí mismo como incapaz de enfrentarse a los acontecimientos de la vida o la preocupación respecto a síntomas no detectados al inicio (Cermák). De esta forma, en la Carta al padre interpreta todo síntoma físico y psicológico experimentado a lo largo de su vida como indicios de su futura enfermedad real, la tuberculosis: "No tenía más preocupación que yo mismo, pero esta preocupación adoptaba formas diversas. Había por ejemplo la preocupación 
por mi salud; comenzó muy pronto; de vez en cuando me asaltaba un leve temor por la digestión, la caída del cabello, una desviación de la columna vertebral, etc.; este temor se incrementaba en infinitas gradaciones hasta que acababa desembocando en una enfermedad real" (Kafka, Carta al padre 4950). De nuevo, la escritura le proporcionará la mejor vía de huida, plasmada en esta ocasión en el espléndido y desgarrador cuento corto titulado, "De noche", escrito probablemente a mediados de 1920:

¡Sumergirse en la noche! Así como a veces se hunde la cabeza en el pecho para reflexionar, hundirse así por completo en la noche. Un pequeño espectáculo, un auto-engaño inocente, es el de dormir en casas, en camas sólidas, bajo techo seguro, estirados o encogidos, sobre colchones, entre sábanas, bajo mantas. En realidad se han encontrado reunidos como antaño una vez, y como después en una comarca desierta, un campamento a la intemperie, una inabarcable cantidad de gentes, un ejército, un pueblo bajo un cielo frío, sobre una tierra fría, arrojados al suelo allí donde antes se estuvo de pie, con la frente apretada sobre el brazo, y la cara contra el suelo, respirando tranquilamente.... Y tú velas, eres uno de los vigías, hallas al prójimo agitando el leño encendido que tomaste del montón de astillas, junto a ti. ¿Por qué velas? Alguien tiene que velar, se ha dicho. Alguien tiene que estar ahí (Kafka, "De noche" 271).

Una última cita, recogida en sus Diarios el día 3 de enero de 1922, por tanto, procedente de un periodo de tiempo no inferior a una década, nos permite apuntar la intensidad de la depresión soportada por Kafka y su frecuencia: "Durante la última semana he tenido algo así como un derrumbamiento total [...] Derrumbamiento, imposibilidad de dormir, imposibilidad de estar despierto, imposibilidad de soportar la vida, o más exactamente, el curso de la vida".

En cuanto a la asiduidad de aparición en la vida del escritor también figura el insomnio, reflejado en todo tipo de documentos, sobre todo, a partir de los estudios de Derecho y el doctorado, ya que el esfuerzo que supusieron para el autor se reflejó en un cambio radical en sus hábitos de sueño. Así, la restricción de horas destinadas a la vigilia desembocará en la llegada del insomnio. Después la escritura se convirtió en una obsesión, en el impulso vital de su existencia, a la que regalaba horas de sueño para construir su obra: "Kafka tenía que escribir porque la escritura era el aire que necesitaba para vivir. Lo respiraba los días en los que escribía. Cuando se dice que estuvo escribiendo durante catorce días, significa que no paró de hacerlo durante catorce días y catorce noches" (Diamant 228). Sus escritos, tanto de creación 
como los más personales, constituyen, sin duda, el eje fundamental en torno al que articula su existencia.

Por este motivo, una vez finalizada la jornada en la compañía de seguros, se centra en cuerpo y alma en la escritura sin apenas concederse descanso: "Noche de insomnio. Ya es la tercera seguida. Me duermo bien, pero una hora después me despierto, como si hubiese puesto la cabeza en un agujero equivocado. Estoy completamente despierto, tengo la sensación de no haber dormido nada o de haberlo hecho sólo bajo una delgada piel, he de afrontar de nuevo la tarea de dormirme y me siento rechazado por el sueño" (Carta a Felice Bauer, 2 octubre 1911).

Pese a su consideración de las dolencias sufridas desde la juventud, como el insomnio o las severas jaquecas, como vaticinios e indicios de la enfermedad que finalmente se lo llevó al otro lado del Estigia, en diferentes momentos las adscribe a la hipocondría, al exagerado autoanálisis y observación de sí mismo: "En los sanatorios estuve a causa del estómago y de la debilidad general, sin olvidar la hipocondría, enamorada de sí misma" (Carta a Felice Bauer, 5 noviembre 1912). O, incluso, años después, cuando ya tiene pronosticada la tuberculosis, le escribirá a Milena esbozando una relación de causalidad entre enfermedad física y mental: "Estoy mentalmente enfermo, la enfermedad pulmonar es sólo un desborde de la enfermedad mental (Carta a Milena Jesenská, 31 octubre 1920).

\section{OPINIÓN SOBRE LA MEDICINA Y LOS MÉDICOS}

La medicina tradicional y los médicos que la practican no gozan del beneplácito de Kafka, tal y como se recoge de forma explícita en diferentes momentos de su obra. Así, en sus Diarios, en la anotación del 5 de marzo de 1912 comenta: "Estos malditos médicos! Tanto decididos a la hora de cobrar y tan ignorantes cuando se trata de curar a los enfermos! -si nunca los abandonaba el talante de negociantes, se conduciría delante de la cama del enfermo como una criatura. Si al menos yo tuviera la energía de fundar una sociedad de medicina natural!". O en una carta a Felice Bauer espeta: "De seis hermanos y hermanas yo soy el mayor, dos hermanos algo más jóvenes que yo murieron cuando eran pequeños por culpa de los médicos, después vino un intervalo en blanco, yo era el único hijo, y transcurridos cuatro, en cinco años se sucedieron las tres hermanas espaciadas entre uno y dos años" (Carta a Felice Bauer, del 19 al 20 diciembre 1912). 
La obra de Kafka publicada en vida se compone de seis títulos, Contemplación (1913), La condena. Una historia (1913), El fogonero. Un fragmento (1913), La transformación (más conocida por La metamorfosis) (1915), En la colonia penitenciaria (1919) y Un médico rural. Relatos breves. De forma póstuma, se publicaría Un artista del hambre. Cuatro historias, a escasos tres meses de la muerte de su autor, todavía revisado por él mismo. El relato que ahora nos interesa es el que da título al libro, del que no existe manuscrito, pero debió de escribirlo entre diciembre de 1916 y mediados de enero de 1917, por los cuadernos en los que se ha encontrado. El texto se publica de forma independiente por primera vez en 1918, dentro del libro en 1920, y posteriormente en el periódico Prager Presse, en el suplemento dominical del 3 de abril de 1921.

Entre las diferentes interpretaciones acerca de "Un médico rural" destaca aquella que lo comprende como una alegoría moral o un intento de reflejar la pérdida de poder del hombre de ciencia frente a la fuerza de la naturaleza. En este sentido, el protagonista reflexiona en diferentes fragmentos; así en cuanto a su función social apunta: "No saben nada de todo esto, y si lo supieran, no lo creerían. Es fácil escribir recetas, pero entenderse con la gente es difícil. Una vez más me han molestado inútilmente, estoy acostumbrado" (Kafka, "Un médico rural" 129) o respecto a la relación entre religión y medicina: "Siempre esperan que el médico haga milagros. Han cambiado sus antiguas creencias; el cura se queda en su casa y desgarra sus dalmáticas una tras otra; pero el médico todo lo puede, piensan ellos, con su hábil mano quirúrgica" (Kafka, "Un médico rural" 131-132). Como también el texto podría significar que el médico solo puede comprender al paciente cuando experimenta lo mismo que éste (al recostarle desnudo junto a él en el relato), que el médico en realidad es una especie de chivo expiatorio o simplemente pretendería mostrar la visión de Kafka sobre la salud y la enfermedad. En el fondo, nos puede estar mostrando que el médico siempre es responsable, en un sentido moral amplio, tanto de su actuación durante la visita al enfermo como de las omisiones en las que incurre (dejar sola y ante un claro peligro a su criada) y debe asumir las consecuencias en cada situación (Álvarez-Díaz 2008; Brancato 1978; Guth 1965). 


\section{LA VIDA COMO ESCRITURA}

El domingo 17 de noviembre de 1912, Kafka experimentó la sensación de no poder levantarse de la cama, de no tener ningún interés por realizar acción alguna. Si a este sentimiento le añadimos los problemas ligados a la escritura de El desaparecido, novela que no terminaba de arrancar y los efectos de la ausencia de carta de su amada Felicia, comprenderemos su estado de total abatimiento. Si además recordamos que su muy querida hermana Ottla, considerada por el escritor como su soporte moral y psicológico en la familia, se había puesto en contra suya por su nula implicación en la fábrica familiar, comenzaremos a ubicarnos en el caldo de cultivo de un célebre relato. Nos faltaría señalar dos notas más: su reciente lectura de la narración El Kondignog, una historia de Johannes V. Jensen, en la que una persona se transforma en un horrendo animal prehistórico y, por último, su conocimiento de la imagen del ser humano degradado a animal, en concreto a un insecto sin utilidad alguna, gracias a la frecuencia con el que el padre la repite en su discurso (Stach 2016). Todas estas circunstancias influyen en la génesis de uno de los relatos más celebres y canónicos de la literatura del siglo XX, La transformación, más conocida por la versión errónea en español de $L a$ metamorfosis.

Entre las diferentes exégesis del relato se ha comprendido como la visión de los avatares de un enfermo terminal en el seno de una familia. La ruptura del orden lógico de los hechos como característica del universo kafkiano despoja a la historia de los detalles relativos a las circunstancias que han conducido a Gregor Samsa a esta situación, como tampoco los motivos constituyen la preocupación de su familia, pese a la desesperación en la que se hunde ante su estado. Entre el surgimiento de los sentimientos más atroces y mezquinos en los distintos personajes destacan las continuas menciones a la enfermedad a lo largo del texto, por ejemplo: "Hoy no se encuentra bien - dijo la madre a este último mientras el padre continuaba hablando junto a la puerta-. No está bueno, créame usted, señor principal. ¿Cómo, si no, iba Gregorio a perder el tren?" (Kafka, La metamorfosis 22); "Por el amor de Dios! -exclamó la madre llorando-. Tal vez se sienta muy mal y nosotros le estamos mortificando [...] Tienes que ir en seguida a buscar al médico; Gregorio está malo" (25) o "Más debió arrepentirse de su proceder, pues tornó a abrir al momento y entró de puntillas como si fuese la habitación de un enfermo de gravedad o la de un extraño" (33). 
Así también descubrimos abundantes comentarios, referencias al dolor y al sufrimiento: "que no cesó hasta que un dolor leve y punzante al mismo tiempo, un dolor jamás sentido hasta aquel momento, comenzó a aquejarle en el costado" (17); "Gregorio se horrorizó al oír en cambio la suya propia, que era la de siempre, sí, pero que salía mezclada con un doloroso e irrepetible pitido" (19). De hecho, la obra no se restringe a la transformación del protagonista, sino que se producen diferentes cambios en todos los actantes que aparecen en la historia. De ahí la línea interpretativa en torno a la metáfora del tránsito de un ser humano sano a un enfermo de gravedad, con todo tipo de cambios individuales, familiares y sociales. Desde su mutación, Samsa experimenta el aislamiento progresivo, la exclusión hasta llegar al ninguneo, a la negación de su existencia, tanto por parte de la familia, como de la sirvienta o del resto de la sociedad. Frente a la extrema desidia e iniquidad en la que incurren los diferentes personajes, Gregor representa el único bastión que actúa con humanidad: "Le vaciaban su cuarto, le quitaban cuanto él amaba: ya se habían llevado el baúl... (41); "Quién, en aquella familia cansada, deshecha por el trabajo, hubiera podido dedicar a Gregor algún tiempo más que el estrictamente necesario? (47); "y sólo sentía hacia ella la irritación producida por la poca atención que se le dispensaba [...] El arreglo de la habitación, que siempre tenía lugar de noche, no podía asimismo ser más rápido. Las paredes estaban cubiertas de mugre, y el polvo y la basura amontonábase en los rincones" (48); "Verdad es que nadie se cuidaba de él" (52); "Ante este monstruo, no quiero ni siquiera pronunciar el nombre de mi hermano; $y$, por tanto, solo diré esto: es forzoso intentar librarnos de él. Hemos hecho cuanto era humanamente posible para cuidarle y tolerarle, y no creo que nadie pueda, por tanto, hacernos el más leve reproche" (54-55). De esta manera, el célebre tópico, muy repetido en cuentos de tradición oral centrados en transformaciones de sus protagonistas humanos en personajes animales que vuelven a su forma primera gracias al amor, adquiere notas irónicas en algunos pasajes hasta desembocar en una trágica y cruel conclusión: la ausencia del esperado beso como manifestación del amor que jamás llegará.

La escritura de Kafka se apoya, entre otros muchos aspectos, en la novelística del realismo del siglo XIX. Su objetivo no radica en la reproducción fidedigna de la realidad, sino que opta por mostrar su fragmentación y pone en entredicho la misma ficción, como apunta T. W. Adorno (1962):

Sus novelas son la anticipada respuesta a una constitución del mundo en la que la actitud contemplativa se ha convertido en ludibrio 
(falseamiento) sangriento, porque la permanente amenaza de la catástrofe no permite ya a ningún hombre la contemplación sin intervención de parte, y ni siquiera la reproducción estética de esa contemplación (50).

Como sabemos gracias al cotejo de sus documentos personales con sus originales, con su creación literaria realizado por algunos de sus estudiosos como Wagenbach (1981) Koch (2009), Stach (2016) o Canetti (2016), Kafka trabajaba de manera obsesiva en pocas semanas o incluso en un breve período de tiempo, normalmente a partir de una idea o de una imagen basada en acontecimientos reales. A estos espacios de máxima intensidad, les sucedían temporadas de sequía creativa, pese a la continuidad de su escritura, plasmada en las largas cartas, anotaciones en los cuadernos o sus diarios. Como muestra significativa podemos citar la escritura en una sola noche del relato "La condena":

Esta historia, "La condena", la he escrito de un tirón durante la noche del 22 al 23, entre las diez de la noche y las seis de la mañana. Casi no podía sacar de debajo del escritorio mis piernas, que se me habían quedado dormidas de estar tanto tiempo sentado. La terrible tensión y la alegría a medida que la historia iba desarrollándose delante de mí, a medida que me iba abriendo paso por sus aguas. Varias veces durante esta noche he soportado mi propio peso sobre mis espaldas. (...) El corroborado convencimiento de que cuando trabajo en mi novela me encuentro en vergonzosas bajuras de la escritura. Sólo así es posible escribir, sólo con esa cohesión, con total abertura del cuerpo y del alma (Diario, 23 septiembre de 1912).

Diferentes constantes del universo kafkiano se congregan en esta narración, desde la inconfundible cartografía que produce su obra, las estructuras jurídicas que se entremezclan con la cotidianidad, pasando por la presencia de la figura paterna o la lógica onírica de la misma acción, siempre contraria a las expectativas del actante-protagonista.

Con el objetivo de poder destinar el máximo tiempo posible a la escritura, el autor de El Castillo decidió implantar un rígido horario tras sus obligaciones laborales en la oficina de seguros. La escritura es la vida. Sin la primera no concibe la segunda. Lluís Izquierdo precisa: "No es él quien va a la escritura, sino ésta la que se cierne sobre él como una nube preñada de las precisas gotas para sobrevivir y -una vez atravesadas las gélidas capas del entorno- cristalizar en la página, escritura frágil y dura como un diamante 
tallado en la consciencia estricta de su provisionalidad" (905). Las palabras del escritor de Praga del 21 de octubre de 1913 anotadas en su diario resultan reveladoras de cómo percibe el transcurso de las horas que no puede destinar a su producción literaria: "Día perdido. Visita a la fábrica de Ringhoffer, seminario de Ehrenfels, luego en casa de Weltsch, cena, paseo, y ahora, a las diez aquí. Pienso continuamente en el escarabajo negro, pero no escribiré".

La creación literaria, la escritura y nada más. La vida como escritura y el mismo autoescribirse. Aquí estriba su profundo cometido. "El tremendo mundo que tengo en la cabeza. Pero cómo puedo liberarme y liberarlo sin roturas. Y es mil veces preferible desgarrarme que retener o sepultar ese mundo dentro de mí. Para eso estoy aquí, eso lo tengo completamente claro" (Diario, 21 junio 2013). En una carta a Felice Bauer del 14 de agosto de 1913 le explica de forma nítida su relación con la literatura: "Yo no tengo interés alguno por la literatura, lo que ocurre es que consisto en literatura, no soy otra cosa ni puedo serlo". El hecho literario como vida y como enfermedad. Por este motivo, necesita abandonar la oficina, los padres y Praga, ya que suponen grandes losas que le retienen y le roban parte del precioso tiempo que debe reservar de forma exclusiva para la creación. Esta autopercepción se reitera como constante también en sus escritos personales, en la correspondencia y en los cuadernos y diarios: "Mi novela soy yo, yo soy mis cuentos" (Cartas a Felice Bauer del 2 enero 1913). En este sentido, prosigue Kafka su reflexión a su prometida de entonces: "La voluptuosidad de renunciar a la más grande felicidad humana por escribir es algo que me atraviesa irresistiblemente todos los músculos. No puedo liberarme" (Carta a Felice Bauer, 2 septiembre de 2013).

La consagración de la existencia al arte se refleja también en la ficción a través de personajes que abandonan cualquier faceta que pueda perturbar su arte, como en la narración "Un artista del trapecio": "Un artista del trapecio había organizado su vida de tal manera que, mientras trabajaba en la misma empresa, permanecía día y noche en el trapecio. [...] Además, era bien sabido que no vivía así por capricho, pues sólo de aquella manera podía estar siempre en plena forma y mantener la suma perfección de su arte" (Kafka, "Un artista del trapecio" 99).

De esta forma, tanto la ficción como los escritos de carácter más personal esbozan una de las constantes de su cotidianidad, la tensión vida-escritura. Las fluctuaciones de esta relación se apuntan en la singularidad que imprimen a su obra y en un precario equilibrio entre ambos extremos de la balanza, pese a la voluntad manifiesta del escritor de conceder a su creación todo el 
protagonismo en detrimento de las circunstancias vitales que van sucediéndose, pues: "Cuando se trataba de literatura no transigía y no estaba dispuesto a aceptar ningún compromiso, pues toda su existencia se veía afectada por ella. No sólo quería ir al fondo de las cosas... él mismo estaba en el fondo" (Diamant 230).

De las múltiples interpretaciones generadas en torno a los escritos del autor de Praga, siempre aparece la ansiedad existencial como un elemento de destacada importancia, incluso, diríamos fundamental en su vida y en su obra. Como si de una sustancia que condicionará su concepción de la enfermedad y de la existencia se tratara, que impregna todo su universo, tanto el físico, de su entorno como el interior.

Asimismo, en todo tipo de escritos encontramos la reiteración de la obsesión identificativa entre vida y obra. De hecho, podríamos afirmar que a través de las miles de páginas que configuran su diario y su correspondencia, va de forma progresiva literaturizándose, como apunta Torrents: "Això, entre altres coses, ha permés de descriure el conjunt de l'obra com un tot, com una llarga, inacabable i inacabada autobiografia de la qual les narracions i els papers confidencials no constituiren sinó una doble versió" (88). Por este motivo, la lectura de textos como las Cartas a Felice y la Carta al padre nos conduce a preguntarnos si Kafka en realidad deseaba casarse con Felice o si quería normalizar sus relaciones paternofiliales. Recordemos a tal efecto, la liberación que el pronóstico de tuberculosis supone al proporcionarle la excusa para romper su relación y consagrarse en exclusiva a la escritura. En esta línea también podemos citar la Carta al padre, reescrita y corregida en diferentes ocasiones de acuerdo con un sentido de profunda técnica narrativa, pese a no enviarla jamás a su receptor. Quizás tampoco constituía el objetivo de su emisor, sino más bien, el recurso a la literatura como única tabla a la que asirse durante el naufragio, y al tiempo, el refugio, la libertad deseada. Más tarde se la enviaría a Milena Jesenská, su traductora al checo, con el resto de su obra de creación. En realidad, esta remesa entraña toda una concepción de su obra, pues presenta sus cartas como literatura:

Con tu aversión atacaste de un modo más acertado mi actividad de escribir y todas aquellas cosas, para ti desconocidas, que se relacionaban en ella. En dicha actividad, había conquistado de hecho cierta independencia respecto a ti, aunque esa independencia recordaba un poco la del gusano, el cual cuando un pie le aplasta la parte trasera, intenta soltarse con la delantera y se arrastra hacia un lado. En cierto modo me sentía a salvo escribiendo, podía respirar; la 
repulsión que, como es natural, sentías también hacia mis escritos, me resultaba excepcionalmente bienvenida (Kafka, Carta al padre 47).

\section{MYCOBACTERIUM TUBERCULOSIS Y ESTANCIA EN ZÜRAU}

El sábado 11 de agosto de 1917 tiene lugar su primera hemorragia, con un cierto grado de complicación, ya que no parece que vaya a paralizarse. El pronóstico del médico, Gustav Mühlstein, en su visita al día siguiente, habla de una fuerte bronquitis, sin embargo, las hemorragias aparecen de nuevo en las siguientes jornadas. Por lo tanto, las opciones se cierran mucho, tal y como le comenta a su hermana Ottla en su carta, unas semanas después:

Tres posibilidades. La primera: enfriamiento agudo, como el doctor afirma y yo niego; ¿enfriarme en agosto? Yo, que no me resfrío nunca. En tal caso, la culpa podría ser de la casa, fría, húmeda, maloliente. La segunda: tisis. Por el momento, el doctor la niega. Pero habrá que ver; todos los habitantes de las grandes ciudades están tuberculosos, sufren neumonía apical (esa es la expresión, como llama cochino a alguien cuando lo que se quiere decir es cerdo), lo cual no es tan grave, se inyecta tuberculina y ya está. La tercera: apenas apunté esta posibilidad, él la rechazó. Y sin embargo es la única correcta, y es compatible con la segunda. En los últimos tiempos he vuelto a sufrir terriblemente la vieja locura, en realidad solo el último invierno ha supuesto una relativa interrupción en cinco años de continuado sufrimiento. [...] Me imagino que la locura ha tenido algo que ver en la hemorragia, puesto que me causaba incesantes insomnios, dolores de cabeza, estados febriles, tensiones, que me han ido debilitando hasta hacerme proclive a desarrollar algo de tipo tísico [...] Éste es pues el estado de esta enfermedad espiritual, tuberculosis (Carta a Ottla, 29 de agosto de 1917).

De esta forma prosigue el autor con el trazado de su línea de reflexión en torno a la posible relación de causalidad entre sus dolencias anteriores y la enfermedad actual. Trata la tuberculosis como una enfermedad espiritual, no como una patología de graves consecuencias, tal como aparece en el siglo XIX y principios del XX con un lectura moral y mitificada por la literatura romántica: “Aquest és l'èxit típic de les morts de tuberculosi en la literatura, i va paral·lel a l'espiritualització inveterada de tuberculosi i a la sentimentalització dels seus horrors" (Sontag 49). En cierto modo, la aparición 
de la tuberculosis confirma las lúgubres premoniciones y Kafka dejará pasar un cierto periodo de tiempo hasta comenzar a comunicar la noticia a los más próximos, tres semanas en el caso de Ottla o un mes en el de Felice Bauer: "El resultado, sin entrar aquí en los múltiples detalles médicos, es que los vértices de ambos pulmones están afectados de tuberculosis. No me ha sorprendido el que se haya declarado una enfermedad, el que haya salido sangre tampoco me ha sorprendido, la verdad es que desde hace ya años estoy atrayendo a la gran enfermedad a fuerza de insomnios y jaquecas, y mi maltratada sangre simplemente ha saltado al exterior (Carta a Felice Bauer, 9 septiembre 1917).

Como vía de curación, Kafka apostó por ir con Ottla a Zürau, pese a las reticencias de los amigos, escépticos ante la posible mejora que un lugar con un clima lluvioso y sin un médico de confianza cerca podría generar y preocupados por cómo resolvería la vuelta de las hemorragias, si se produjera. Los presagios de estas voces resultaron certeros, pues la gravedad de la enfermedad del autor, unida a la ausencia de comodidades y médicos del nuevo domicilio, desembocan en la parálisis de la escritura. Las páginas del diario permanecerán en blanco, sin una sola anotación, hasta junio de 1919 en que inaugura un nuevo cuaderno, destinado de forma exclusiva a anotaciones literarias.

No obstante, la tuberculosis tendrá para el escritor al menos un efecto secundario beneficioso, ya que le proporcionará la justificación para la retirada social, laboral, e incluso, amorosa. Ya no debe preocuparse por cómo no casarse con Felice y rompe la relación tras muchos años de noviazgo. De hecho, en una carta al editor Kurt Wolff, el 4 de septiembre de 1917 afirmará al respecto: "Es casi un alivio". En este sentido Susan Sontag nos apunta el mito que se produce en determinadas enfermedades y, en especial, su efecto romántico como productora de una justificación de la creatividad: "Els romàntics s'inventaren la invalidesa com a pretext per a l'oci, i poder abandonar les obligacions burgeses per tal de viure solament per a l'art. Era una forma de retirar-se del món sense haver de prendre responsabilitats per a les decisions" (41).

Por su parte, los cuidados de la hermana en la granja que regentaba en Zürau le proporcionan la protección y el afecto necesario para proseguir con la creación, según le explica al amigo Max Brod (14 de septiembre 1917): "Ottla literalmente me lleva sobre sus alas a través del difícil mundo". Así, abandona la escritura del diario para inaugurar unas notas formuladas de manera contundente en torno a todo tipo de temática, desde cuestiones morales o religiosas a temas literarios. Se trata de unos cuadernos escolares 
azules que hoy llevan el nombre de Cuadernos en octavo $G$ y $H$, en los que escribe una especie de aforismos, reflexiones y notas muy interesantes, pero quizás poco conocidas por los lectores como: "Voy a la deriva. El camino verdadero pasa por un alambre que no está tendido en lo alto, sino muy cerca del suelo. Parece hecho más para tropezar que para andar por él" (Kafka, Cuadernos en octava 47). O: "El lamento junto al lecho de muerte es en realidad el lamento por el hecho de que no se ha producido una muerte en el sentido verdadero, y seguimos teniendo que conformarnos con esa muerte, seguimos jugando el juego" (131). A Max Brod debemos la publicación del conjunto de reflexiones de Zürau, entresacadas de su legado, en 1931, a las que tituló con un tono esotérico: Consideraciones acerca del pecado, el dolor, la esperanza y el verdadero camino.

Según parece, la tuberculosis en su fase inicial le facilitó a Kafka no solo la legitimación de su huida de determinados ámbitos, sino sobre todo, una suerte de liberación en diferentes sentidos con positivas consecuencias en su estado de ánimo, según se desprende de la correspondencia con Brod: "Si no temiera inquietarte con esto te diría que tus cartas dan testimonio de una gran calma. Ya lo he dicho...una prueba de que ni siquiera temo de verdad que esto, o cualquier otra cosa, pueda inquietarte. Eres feliz en tu desgracia" (Carta de Brod a Kafka, 10 octubre de 1917). De esta manera, el permiso para restablecerse de la enfermedad concedido por el Instituto de Seguros de Accidentes de Trabajadores de tres meses se incrementa hasta casi ocho meses. El día treinta de abril Ottla le lleva a la estación y el 2 de mayo Kafka se presenta en el despacho de su jefe con una ligera tos, pero con un aspecto mucho más saludable del que había tenido en años.

\section{LA PANDEMIA DE GRIPE DE 1918}

A finales de la Primera Gran Guerra, Kafka contrajo la enfermedad pandémica conocida como gripe española o también denominada, la epidemia de gripe de 1918. En las circunstancias en las que se encontraba y dada la gran mortalidad que provocó, resulta casi un milagro que pudiera sobrevivir, pues supuso un grave problema en todo el mundo, ya que a diferencia de otras epidemias de gripe cuya población de riesgo se había cifrado sobre todo, en niños y ancianos, ahora muchas de las víctimas fueron jóvenes y adultos saludables. De hecho, ha sido calificada como la pandemia más devastadora de la historia contemporánea, con cifras de mortalidad de entre 
veinte y cuarenta millones de personas en apenas un par de años. El nombre procede de la atención recibida por parte de la prensa en España, bastante mayor que en el resto de Europa, ya que no existía la censura de guerra y se informó con bastante libertad. Entre otros personajes ilustres afectados, el rey Alfonso XIII también la sufrió.

Cuando la pandemia se encontraba en el punto más álgido, el 14 de octubre de 1918, el médico Heinrich Kral comprobó que Kafka tenía más de cuarenta grados de fiebre. A partir de este momento, su familia optó por ponerlo en aislamiento, sin la posibilidad de visitas de amigos e íntimos, ya que se esperaba que comenzara a toser sangre en breve y se desencadenara el final. Afortunadamente, esta decisión familiar lo salvó de la exposición a otros enfermos y personal sanitario, y en consecuencia, del posible contagio, por lo que tras un mes de intensos cuidados, pudo superarla. Débil, pero sobrevivió.

\section{ALGUNOS SANATORIOS Y HUIDA DE PRAGA}

Desde el diagnóstico de tuberculosis, Kafka pasa por varios sanatorios y estancias, siempre de acuerdo con la premisa de escapar de Praga. No se trata de su primera visita a establecimientos de esta índole, pues cuenta con la experiencia previa de su paso por el de Jungborn, casi una década antes o el muy célebre de Dresde, Weisser Hirsch. Al autor de El proceso le habían aconsejado reposo absoluto, por lo que solicita su jubilación anticipada, pero le es denegada; sin embargo, se le conceden tres meses que pasa en Zürau, como hemos visto, al noroeste de Bohemia, en una finca agrícola con su hermana Ottla. A partir de noviembre de 1918, durante cuatro meses vive en una pensión de Libechov. De noviembre a diciembre de 1919 viaja a Schlesen (Želízy), Bohemia, a una treintena de kilómetros al norte de Praga y en este sanatorio escribe y reescribe la célebre Carta al padre. Recordemos que el arsenal terapéutico médico del momento no contaba aún con antibióticos ni menos todavía con tuberculostáticos, y el tratamiento básicamente consistía en dietoterapia o cura climática.

En 1920 descansa de abril a junio en Merano (Italia) y del 20 de diciembre hasta el 27 de agosto de 1921 permanece en el Sanatorio Villa Tatra, en Tatranské-Matliary (Alto Tatra), por primera vez entre enfermos de tuberculosis. La recomendación procede del doctor Kral y se basa sobre todo en el clima, ya que el sol brilla sobre aquellas cumbres montañosas, pero también en el equipo médico. En la elección final de Kafka pesan sin 
embargo otras razones, entre ellas las cuestiones económicas, unidas a una cocina bastante vegetariana y la posibilidad de trabajar en el huerto, afición procedente de Zürau. En su correspondencia, el amigo Max Brod le insiste en la necesidad de comportarse como un buen paciente y de respetar, al menos, los tres meses previstos inicialmente, como una especie de "servicio militar" contra la enfermedad. Su punto de vista sobre el sanatorio difiere de la perspectiva del doctor Kral, ya que considera que este sanatorio no reúne todas las condiciones necesarias, ni tampoco el personal médico, precisamente no especialista, opinión que comparte toda la familia.

Fruto de su estancia es la toma de conciencia de Kafka respecto a la tuberculosis, ya que casi todos los huéspedes la padecen y algunos en estados muy avanzados, tal y como refleja en una carta de finales de enero de 1921 a Brod:

Lo que se ve allí en la cama es mucho peor que una ejecución, incluso que una tortura. La tortura no la hemos inventado nosotros mismos, sino que la hemos copiado de las enfermedades, pero ningún individuo se atreve a torturar como ella tortura durante largos años, con interrupciones artificiales para que no ocurra demasiado rápido y -lo más singular- el torturado es obligado a prolongar la tortura por propia voluntad, a partir de su pobre intimidad. Toda esta vida miserable en la cama, la fiebre, las dificultades respiratorias, tomar medicamentos [...] Y los familiares y los médicos y los visitantes materialmente han construido andamios por encima de esta pira, que no arde pero que está en estado incandescente, para poder visitar, apaciguar, consolar y animar al torturado para que sufra miserias aún mayores sin correr el riesgo de contagiarse (Carta a Max Brod 27 de enero de 1921).

Pese a todo, el autor se encontraba allí a gusto y establece una suerte de empatía con el resto de los enfermos, una especie de solidaridad entre infectados de tuberculosis y de forma concreta, una buena amistad con dos residentes del centro, aquejados de la misma enfermedad, Arthur Szinay, un joven de poco más de veinte años, admirador de Brod, y el estudiante de medicina de entonces Robert Klopstock.

En cuanto a su salud, si bien se constata un cierto incremento de peso, no podemos calificarla como buena, ya que en determinados momentos padeció estados de insuficiencia respiratoria y durante bastantes días tuvo episodios de fiebre. Ante este cuadro, los directivos del Instituto de Seguros 
de Accidentes de Trabajo optaron por ir prorrogando el permiso de estancia hasta agosto de 1921 con el salario completo. La información que enviaba a Praga sobre la enfermedad y su estado cada vez se volvía más esporádica, con la excepción de las misivas intercambiadas con Brod bajo su constante presión en la relación epistolar. Así, le comenta: "Tú siempre escribes sobre curarme. Para mí, eso está fuera de toda posibilidad" (Carta a Max Brod, 3 de mayo de 1921).

La llegada de agosto trae consigo un nuevo aplazamiento tanto de su regreso a Praga como al mundo laboral. El 14 de agosto de 1921, aproximadamente a una semana de su retorno al trabajo, tuvo fiebre y ataques de tos agudos, por lo que tuvo que disculparse de nuevo ante la imposibilidad de incorporarse. Finalmente, el 26 de agosto coge el tren para volver a su ciudad natal con una certeza: la necesidad de ocultar a los padres la realidad de la experiencia vivida. La convivencia diaria con la tuberculosis, tanto por su propio estado, como a través de otros enfermos, ha desembocado en una clara toma de conciencia respecto a la gravedad de la enfermedad. Meses después escribirá, sin fechar, el siguiente documento:

Queridísimo Max, mi último ruego: quema sin leerlos absolutamente todos los manuscritos, cartas propias y ajenas, dibujos, etcétera, que se encuentren en mi legado (es decir, en cajas de libros, roperos, escritorios de casa y de la oficina, o cualquier otro sitio donde pueda encontrarse algo y te llame la atención), así como todos los escritos y dibujos que tú u otros, a los que debes pedírselo en mi nombre, tengáis en vuestro poder. Deben al menos comprometerse a quemar en persona las cartas que no quieran entregarte. Tuyo. FRANZ KAKFA ${ }^{1}$ (Stach, vol. II, 1861).

A partir de julio de 1922, tras varias recaídas y permisos, el doctor Kodyn, médico de la empresa de seguros le concede la jubilación anticipada. Este verano lo pasa con su hermana Ottla en Planá, al sur de Bohemia, a solo cien kilómetros de Praga. El amigo Oskar Baum lo invitó a Georgenthal, en Turingia, pero después de varias noches insomnes rechaza ir y le comenta a Brod: "Con ello se decidirá que no debo salir de Bohemia, en el futuro quedaré limitado a Praga, luego a mi habitación, luego a mi cama, luego a

1 Max Brod encontró esta primera disposición testamentaria cuando revisó los papeles de Kafka después de su muerte. 
una determinada posición, luego a nada" (Carta a Max Brod, 5 de julio 1922). El invierno de 1922-1923 resulta bastante duro, con algunos días buenos seguidos de semanas en cama. En la casa familiar la mayoría de las jornadas las pasa acostado con dos mantas, un edredón y bien próxima, una estufa que la criada mantiene encendida. La diferencia con la década anterior resulta más que evidente, pues en ella Kafka dormía incluso en invierno con la ventana abierta y este ambiente le habría parecido una insoportable imposición. De hecho, en sus obras las estancias sobrecalentadas siempre son metáforas de la falta de libertad y rechazo a la vida, como por ejemplo se aprecia en "Un médico rural". No obstante, ahora el fantasma de la neumonía le aterra y permanece tapado en el domicilio, por lo que no le queda excesivo tiempo ni tampoco fuerzas para dedicarse a las dos tareas que en ese momento consideraba más importantes, por un lado la literatura y por otra, el hebreo. La primavera trae consigo una mejoría en forma de desaparición de la fiebre casi por completo y pasa las vacaciones de verano de 1923 con su hermana Elli, en Müritz, un balneario de aguas, con playa y bosque, en la costa del Báltico. Si bien el clima nórdico no resulta el más aconsejable para su salud, por otra parte le regalará un elemento vital para su periplo existencial, ya que en él conocerá, el 13 de julio, a la que será su compañera hasta su muerte: Dora Diamant. Por tanto, estancia no muy saludable desde la óptica de la enfermedad, pero desde el punto de vista anímico muy provechosa, marcada por el inicio de la relación.

Del 23 de septiembre de 1923 a enero de 1924 vive primero en Miquelstrasse, en un alojamiento de una habitación amueblada con un gran mirador que Dora le busca y, poco después, en Grünewaldstrasse 13, de dos habitaciones, en Berlín-Steglitz; de febrero a marzo en Heidestrasse 25-26, en Berlín-Zehlendorf. Las diferentes viviendas las tuvieron que abandonar por la presión de los caseros y la subida de precios, salvo la última. A partir de la noche de Navidad de 1923 sufrió fiebre, ataques de tos y su estado empeoró. La pérdida de peso era continua. Si a su estado le sumamos las circunstancias por las que atraviesa en este momento histórico Berlín, asolada por la inflación y con muchos problemas y tensiones sociales, tendremos quizás una de las peores épocas para trasladarse a la capital alemana. En este contexto, el escritor intenta esconder las evidencias relativas al avance de su enfermedad: “¿Voy a abandonar todas estas cosas sólo porque tengo una temperatura un poco alta, debida al invierno tan desacostumbrado que hemos tenido, y porque el tío ha estado aquí cuando hacía mal tiempo y sólo una vez me ha visto al sol, y algunas veces en cama, como también ocurrió 
el año pasado en Praga?" (Postal a Hermann y Julie Kafka, 1 marzo 1924). Finalmente, su tío Siegfried Löwry pudo convencer a Dora y Kafka para volver a internarlo en un sanatorio, en el que la familia asumiría todos los gastos. De esta manera, el 17 de marzo en la estación de Anhalt se encuentran Kafka, Dora, Brod y Robert Klopstock (años después de la muerte de Kafka se graduará como neumólogo). El escritor ya no volvería más a Berlín y las anotaciones y escritos realizados en la gran ciudad se han perdido.

A partir del 20 de marzo de 1924, Kafka presenta una disfonía que le conducirá posteriormente a la afonía. Se traslada a Wienerwald, sanatorio pulmonar que gozaba de una buena reputación internacional, pero que al escritor le desagrada profundamente e incluso, le comenta a Brod los calificativos que para él lo definen: "perverso y agobiante", como tampoco el equipo médico que lo atiende goza de su confianza: "el uno tiránico, el otro blando, pero ambos creyentes en la medicina y desvalidos en la necesidad" (Carta a Max Brod, 20 de abril 1924). Los crecientes dolores en la laringe suponen el indicio clave de la extensión de la enfermedad, por lo que es derivado a Viena a la clínica del profesor Hajek (quien atendiera en 1923 a Sigmund Freud de su cáncer de maxilar), uno de los mejores laringólogos de la época. Después de varias pruebas, el diagnóstico resulta claro: tuberculosis laríngea. En este momento, Kafka tiene a su alcance todas las posibilidades de intervención que el diagnóstico permite, sin embargo, opta por abandonar el hospital el día 19 de abril.

A continuación se instalará en el sanatorio del profesor Hoffmann en Kierling-Klosterneuburg, cerca de Viena. Según parece, el establecimiento tenía muchas ventajas, entre otras, la ausencia de horarios y la posibilidad de contar con la compañía de Dora Diamant en todo momento. En este lugar, a consecuencia de la enfermedad, pierde el habla y la posibilidad de ingerir alimentos. Los dolores en la laringe le resultaban prácticamente insoportables y convertían la comida y la bebida en un tormento. Nos ha llegado un dictamen del doctor Beck, escrito después de visitar a Kafka para informar a su amigo Weltsch:

Ayer fui llamado a Kierling por la señorita Diamant. El señor Kafka tenía dolores muy fuertes en la laringe, especialmente al toser. Al ingerir alimento los dolores aumentan de tal modo que tragar se hace casi imposible. Pude constatar en la laringe un proceso tuberculoso desintegrador, que incluye también una parte de la epiglotis. En este estado no cabe pensar en intervención quirúrgica alguna, y he administrado una inyección de alcohol en el nervio laríngeo 
superior. [...] Comprendo, desde el punto de vista psicológico, que la señorita Diamant, que se ocupa del enfermo de manera sacrificada y conmovedora, tenga el deseo de llamar a consejo a Kierling a cierto número de especialistas. Tuve que dejarle claro que el doctor Kafka se encuentra, tanto en lo que respecta al pulmón como a la laringe, en un estado en el que ningún especialista puede brindarle ya ayuda alguna, y que sólo es posible aliviar los dolores con morfina (Carta de Oskar Beck a Felix Weltsch, 3 de mayo de 1924. (Cit. en Brod, 179 y Stach, 2226).

Ante esta situación, su amigo Robert Klopstock, paciente de tuberculosis con experiencia, acude en la ayuda de Dora a Kierling. En estas semanas se encuentra débil, pero lee y trabaja pese a los esfuerzos que estas actividades le suponen ahora. Esperaba con impaciencia las galeradas del libro de relatos Un artista del hambre para efectuar las correcciones por su propia mano mientras estuviera consciente. La lectura de la narración "Un artista del hambre" le generaba una profunda inquietud, pues explica la historia de un hombre que ya no quiere comer, escrita por un hombre que ya no puede comer. Para Kafka, que con frecuencia había recurrido en su obra a la metáfora de la denegación de la alimentación, resultaba una paradoja difícil de soportar.

Durante el poco tiempo vivido juntos como Dora y Franz, el autor escribe entre otros relatos "La obra", también conocido como "La guarida", que no llegó a terminar, como muchos otros. A propósito de este texto, Roberto Calasso nos sugiere: "El tono es el de un balance escrupuloso, como de quien dijese: si de verdad queréis saber cómo fue mi vida aquí encontraréis el diario de a bordo, pero despojado de todo carácter accidental, reducido a la geometría de los movimientos, por encima y por debajo de la capa de musgo que ocultaba el acceso a la guarida" (73).

\section{FINAL Y CONCLUSIONES}

En la correspondencia de los últimos meses de vida de Kafka, encontramos un claro deseo de tranquilizar a los padres: "La temperatura bajará, pues tengo que tomar piramidón tres veces al día, la tos mejorará, pues me dan un medicamento para combatirla, me han reconocido la garganta, parece que no es nada grave, pero de todos modos aún no sé nada concreto, por lo demás también me dan un remedio para ella" (Carta a los padres, 7 abril 1924). En este sentido, llama la atención la preocupación del paciente por los gastos 
de la terapia, como se refleja en la frecuencia con que introduce comentarios en torno al elevado precio de los distintos tratamientos.

Un día antes de su muerte, el día 2 de junio de 1924, escribe la que se considera su última carta, con una primera parte, totalmente alejada de la enfermedad, centrada en el recuerdo de momentos agradables de su vida y en la que por encima de todo intenta disuadir a los padres de una visita al sanatorio:

Todo está en los mejores comienzos -últimamente el profesor ha comprobado una considerable mejoría de la laringe. [...] pero ni siquiera los mejores comienzos son nada; si uno no puede mostrar a los visitantes- y sobre todo a unos visitantes como vosotros- unos progresos grandes, innegables, comprobables también por los ojos del profano, entonces es mejor dejarlo. Así, pues, mis queridos padres, ¿no os parece que por el momento lo dejemos? (Kafka, Carta a los padres 2 junio 1924).

Conocidas las circunstancias, estamos de acuerdo con Dora que acaba la carta: "Le quito la carta de las manos. Ha sido una gran hazaña, con todo". Sin duda, una clara muestra de la lucha agónica del escritor hasta el último momento.

Después vendrá la prohibición de hablar y deberá comunicarse mediante escritos que se han conservado. El día de su muerte exige una inyección de morfina y cuando se le niega dice: "Máteme; si no, usted es un asesino". Al amigo Klopstock le exige: "Siempre me lo ha prometido, desde hace cuatro años". Muere en Kierling.

El 11 de junio sobre las cuatro de la tarde, Kafka es enterrado a las afueras de Praga, en el nuevo cementerio judío de Strasnice. Cuando ocho días después tuvo lugar un acto en memoria del escritor de Praga, Johannes Urzidil explica de forma pionera un aspecto fundamental de su escritura: "Si ha habido un caso de absoluta congruencia entre vida y arte, ha sido el de Franz Kafka" (63). En este sentido también se pronunciará Walser, "En el caso de Kafka, se ha de explicar la vida desde la obra, en cambio, la obra puede renunciar a la clarificación a través de la realidad biográfica" (89).

De acuerdo con la hipótesis que esbozábamos al inicio debemos concluir estas páginas con su total verificación, esto es, la existencia de una íntima relación entre vida y obra que llega hasta el punto de que el conocimiento de la obra y de su vida se iluminan de una manera mutua. Literaturiza su vida al igual que su literatura constituye una parte intrínseca y consustancial de su biografía. Es un todo. Constantemente se escribe a sí mismo. De hecho, en 
relación con el objetivo de este trabajo debemos afirmar que pocos ejemplos encontramos en la literatura con un corpus tan compacto como los escritos personales y la obra de creación como en el autor de Praga, en el que las fronteras de tipología textual o de género literario se difuminan. Tal y como ha demostrado el análisis realizado, en sus diarios o su correspondencia encontramos textos, personajes y fragmentos que luego aparecen en su obra narrativa o viceversa. Su objetivo vital, su gran obsesión es la escritura. Y, por tanto, reescribirse constituye como su única salida ante la existencia.

\section{BIBLIOGRAFÍA}

Adorno, Theodor. Notas de literatura. Barcelona: Ariel, 1962.

Álvarez-Díaz, Jorge. "Un médico rural: una posible lectura ética en el 125 aniversario del nacimiento de Franz Kafka". Gaceta Médica de México 144. 6 (2008): 549-559.

Brancato John J. "Kafka's A country doctor: a tale for our time". Studies in Short Fiction 15 (1978): 173-176.

Brod, Max. Kafka. Barcelona: Emecé, 2000.

Calasso, Roberto. K. Barcelona: Anagrama, 2005.

Canetti, Elias. El otro proceso. Las cartas de Kafka y Felice. Madrid: Nórdica, 2019.

Čermák, Petr. "Las enfermedades de Kafka: vida, lengua y literatura". eHumanista/IVITRA 11 (2017): 273-287.

Diamant, Dora. "Mi vida con Franz Kafka". Koch, Hans-Gerd. Ed. Cuando Kafka vino hacia mí. Barcelona: Acantilado, 2009. 223-237.

Fichter, Manfred M. "The anorexia nervosa of Franz Kafka". International Journal of Eating Disorders 6 (1987): 367-377.

"Franz Kafka's anorexia nervosa". Fortschritte der Neurologie-Psychiatrie 56 (1988): 231-238.

Ekbom, Torsten y K. Ekbom. "Did Franz Kafka suffer from cluster headache?". Cephalalgia 24 (2004): 309-311.

Guth, Hans P. "Symbol and contextual restraint: Kafka's "Country doctor". Proceedings of the Modern Language Association of America 80 (1965): 427-431.

Iruela, Luis. M., "La anorexia de Kafka". Jano (2011): 90-92.

Izquierdo, Lluís. "Kafka". Jordi Llovet. Ed. Lecciones de literatura universal. Madrid: Cátedra, 1995. 901-909.

Jensen, Johannes V. Racconti. Milán: Fratelli Fabbri, 1990.

Kafka, Franz. Carta al padre. Barcelona: Lumen, 1974.

Cartas a Felice y otra correspondencia de la época del noviazgo. Madrid: Alianza, 1978 . 
La metamorfosis y otros relatos. Barcelona: Orbis, 1982.

Obras escogidas. Barcelona: Círculo de Lectores, 1983.

Diaros: 1910-1923. Barcelona: Edicions 62, 1988.

Cartas a Max Brod (1904-1924). Madrid: Grijalbo Mondadori, 1992.

Cartas a los padres de los años 1922-1924. Barcelona: Tempestad, 1992.

Diarios. Carta al padre. Barcelona: Galaxia Gutenberg/Círculo de Lectores, 2000. Cartas a Milena. Madrid: Alianza Editorial, 2015.

Cuadernos en octava. San Carlos: Cielonaranja, 2016.

Koch, Hans-Gerd. Ed. Cuando Kafka vino hacia mí. Barcelona: Acantilado, 2009.

Mora, Miguel. "Kafka era un neurótico, pero tenía una estrategia. Entrevista a Reiner Stach". El País (7-VI-2003).

Stach, Reiner. Kafka. Vol. I y II, Barcelona: Acantilado, 2016.

Sontag, Susan. La malaltia com a metàfora. Barcelona: Empúries, 1997.

Torrents, R. "Kafka, confident". Franz Kafka en els seus millors escrits. Barcelona: Miquel Arimany, 1976. 87-90.

Urzidil, J. Tríptico de Praga. Valencia: Pre-Textos, 1997.

Wagenbach, K., Kafka. Madrid: Alianza, 1981.

Walser, M. Descripción de una forma: ensayo sobre Franz Kafka. México: Coyoacán, 2000. 